\title{
B55 Fetus Papyraceous - A Case Report With Maternal Coagulopathy And Successful Maternal and Fetal Outcome
}

\author{
MST. NAZMUNNAHER MINA ${ }^{1}$, FERDOUS ARA (SHUCHI) ${ }^{2}$, AFROZA KHANUM ${ }^{3}$, TAHSIN ISLAM ${ }^{4}$, \\ SABIHA SULTANA ${ }^{5}$, UMMUL NUSRAT JAHAN ${ }^{6}$, SUFIA BEGUM ${ }^{7}$
}

\begin{abstract}
:
Fetus papyraceous is defined as a compressed fetus, mummified, parchment-like remains of a dead twin or triplet that is retained in-utero after intrauterine death in the second trimester. We report a case of one fetus papyraceous with maternal coagulopathy and no maternal and fetal complications in the post-partum period.
\end{abstract}

Keywords: Fetal death, Fetus papyraceous, Maternal coagulopathy, Twin pregnancy

\section{Introduction:}

The retention of a mummified parchment- like remains of a dead fetus(es) in multiple pregnancy in the second trimester of pregnancy in association with a viable twin is known as fetus papyraceous. ${ }^{1,2}$ Its incidence is 1 in $17000-20000$ pregnancies or $2.3 \%$ of all twin pregnancies. ${ }^{2,3}$ The incidence quoted is likely to be higher in Nigeria, a country with the highest twinning rate in the world. ${ }^{4}$ Disseminated intravascular coagulation (DIC) which complicates demise of singleton pregnancies especially if prolonged is uncommon with fetus papyraceous. ${ }^{5}$

The advent of real-time ultrasound using the intravaginal probe permitted the diagnosis of multiple gestations as early as 4 weeks after conception. In late second and third trimesters, it is not always possible to diagnose, fetus papyraceous by ultrasound examination. ${ }^{6}$

If, fetus papyraceous is diagnosed antenatally, serial evaluation of the surviving fetus by sonography, biophysical profile, doppler, and maternal coagulation factors should be done serially. Zygosity and chorionicity evaluation should be performed antenatally. The timing and procedure for the termination of a pregnancy with a surviving twin are determined primarily by the maturity of the fetus and type of the placenta. ${ }^{7}$ In many cases of fetus papyraceous, there are no complications to the mother or the surviving twin. Expectant management with close maternal and fetal surveillance is advised.

Maternal consumptive coagulopathy as a complication of a late fetal demise is a rarely reported complication. ${ }^{8}$ The possible explanation for such a low incidence of consumptive coagulopathy is the short relative interval from death until delivery of the surviving fetus. Gross disruption of the maternal coagulation mechanism rarely develops within 1month after the fetal death, although, if retained longer, approximately $25 \%$ will develop a coagulopathy. However, in many cases of fetus papyraceous, there are no complications to the mother or the surviving twin.

\section{Case Report:}

A 26 year old woman, P 0+2(MR, SA), presented to our department with secondary infertility. After assessment \& preliminary treatments, ovulation induction was given with letrozol $(2.5 \mathrm{mg})$. After first

1. Assistant Professor, Dept. of Obstetrics \& Gynaecology, Delta Medical College, Dhaka

2. Professor \& Head, Dept. of Obstetrics \& Gynaecology, Delta Medical College, Dhaka

3. Associate Professor, Dept. of Obstetrics \& Gynaecology, Monno Medical College, Manikgonj

4. Medical Officer, National Institute Of Neuroscience \& Hospital, Dhaka

5. Assistant Professor, Dept. of Obstetrics \& Gynaecology, Delta Medical College, Dhaka

6. Associate Professor, Dept. of Obstetrics \& Gynaecology, Delta Medical College, Dhaka

7. Associate Professor, Dept. of Obstetrics \& Gynaecology, Delta Medical College, Dhaka

Address of Correspondence: Dr. Mst. Nazmunnaher Mina, Assistant Professor, Dept. of Obstetrics \& Gynaecology, Delta Medical College \& Hospital, Dhaka; Email: nazmunnahermina@gmail.com; Contact no.: +8801712001032 
cycle, she conceived. During first trimester (11 weeks), USG showed twin pregnancy. A 28 weeks USG showed IUD of one twin and live second twin. She and her husband were counseled about her condition and risks to mother and fetus were explained on continuation of the pregnancy. She was followed up regularly for infections, consumption coagulopathy and also for the well-being of live twin. She was managed conservatively with monitoring of coagulation profile every fortnight and ultrasonography every three weeks. She was advised to keep strict count of daily fetal kick movements and report immediately to the emergency room in case of decreased or absent movements. At 32 weeks of gestation she was given two doses of $12 \mathrm{mg}$ oradexon intramuscular injection 24 hours apart to achieve fetal lung maturity.

Biophysical profile were done thereafter to ensure safety of the live fetus. However, scan done at 31 , 34 and 36 weeks of gestational age failed to visualize the dead twin due to compression by live fetus. In later months, after 30 weeks, her coagulation profile was abnormal. Her bleeding time, clotting time, Prothrombin time and APTT were normal. But gradually her platelet count was decreased and FDP, D-Dimer were increased. Baby was IUGR and breech presentation. At 36 weeks FDP was $8.9 \mu \mathrm{g} / \mathrm{L}$, DDimer was $200 \mathrm{ng} / \mathrm{L}$ and platelet count -200000/ cumm which was at 30 weeks $284000 /$ cumm.

Consultation was done with haematologist and keeping ready 3 units of fresh blood, Caesarean section was done at 36 weeks. She delivered a female baby weighing $1.9 \mathrm{~kg}$ with APGAR score of $8 / 10 \& 9 / 10$ at $1 \& 5$ minutes respectively. Placenta and papyraceous fetus were delivered manually.

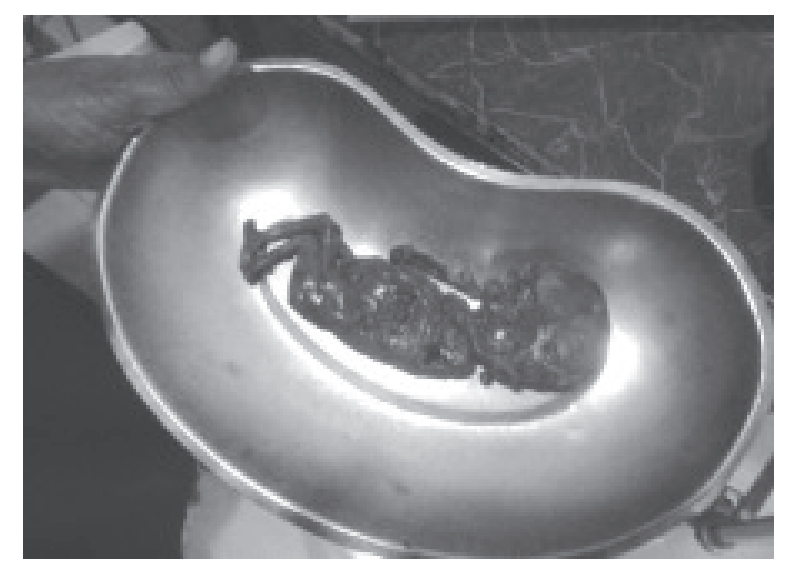

Fig.-1: Fetus papyraceous
There was no immediate third stage complications noted. The placenta weighed $450 \mathrm{gm}$. The papyraceous twin was about $15 \mathrm{~cm}$ in length, flattened parchment like and compressed. The mother and normal baby were discharged with uneventful postpartum period. She was followed up for 6 weeks and there was no further complication.

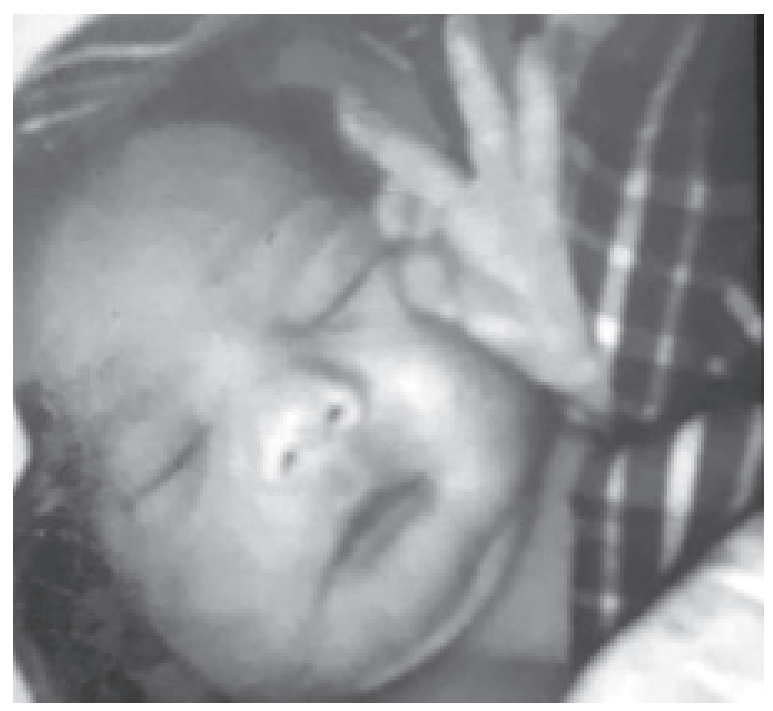

Fig-.2: Healthy baby at day 1

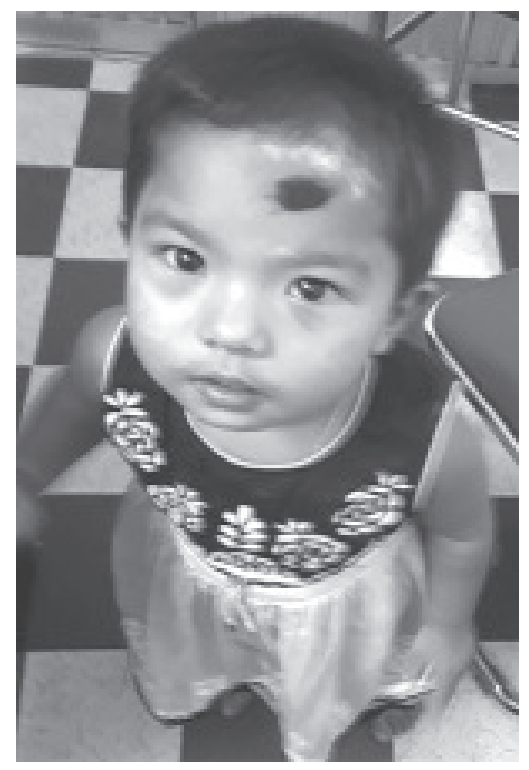

Fig.-3: 2 years old

\section{Discussion:}

Fetus papyraceous is a rare entity observed in 1 in 17,000 to 20,000 pregnancies seen as a result of antenatal demise of one of the fetuses in a multifetal gestation. The dead fetus got compressed between 
the membranes with absorption of the fluid content of the dead fetal and placental tissues rendering it tiny, flattened and mummified. This condition can pose a risk to both the mother and the remaining fetus during the course of pregnancy.

The condition is difficult to diagnose if antenatal visits with obstetric ultrasound are not done, thus many a times diagnosed only after delivery. Multifetal gestation can be diagnosed as soon as 4 weeks after conception with Transvaginal Sonography. In late second and third trimesters it is not always possible to diagnose fetus papyraceous by ultrasound examination.

Perinatal mortality of monochorionic twin pregnancies is higher than with dichorionic twins. McPherson and colleagues investigated an association between chorionicity and intrauterine fetal demise (IUFD) of one or both fetuses in twin pregnancy. The study was performed on 2161 twin pregnancies; 86 had at least 1 IUFD and 32 had a double fetal loss. Consequently, they found that monochorionic pregnancies had an increased risk of a single demise and a double demise, mostly at 24 weeks of gestation. This led them to put forward that monochorionic twins carry an increased risk of fetal death compared to dichorionic twins.

Complications of a fetus papyraceous on the surviving twin include intrauterine growth restriction, congenital disorders, cord complications, pre-term labour, and prematurity. Risk of cerebral impairment of the surviving twin is about $20 \%$ with corresponding increase in the incidence of cerebral palsy.

Maternal complications include pre-term labor, infection from a retained fetus, severe puerperal hemorrhage, consumptive coagulopathy, and obstruction by a low-lying fetus papyraceous causing dystocia leading to caesarean delivery. It is necessary to make a timely diagnosis to prevent severe complications. It is important to reassure the patient that normal outcome is expected in most of the cases. Maternal consumptive coagulopathy as a complication of a late fetal demise is a rarely reported complication. The mechanism suggested to explain coagulopathy associated with IUFD involves release of tissue thromboplastin from the fetal circulation into the mechanical circulation ${ }^{9,10}$. Thromboplastin is thought to stimulate the maternal coagulation system causing intravascular consumption of clotting factors and platelets. A corresponding increase in activity of the fibrinolytic pathways leads to breaks down of fibrinogen to form fibrin degradation products (FDPs) and fibrin-fribin dimers (D-dimers).

Depending on the gestational period at which fetal death occurs, there are three forms of this complication; vanishing twin syndrome in the first trimester, fetus papyraceus in the second trimester and the macerated twin in the third trimester. In most cases, death occurs in the second trimester. [11] The degree of compression depends on the time span between the fetal death and delivery; the larger the fetus, the more difficult it is to become a fetus papyraceus.[12] Different causes for the intra uterine death of one fetus include twin-twin transfusion syndrome, membranous or velamentous cord insertion, true cord knot, cord stricture, placental insufficiency, and congenital anomalies. ${ }^{13}$

Close follow up is of utmost importance. Coagulation profile should be checked every 2 weeks and the surviving twin's well being should be monitored closely with ultrasound, biophysical profile and Doppler. Any anomalies in the surviving twin should be ruled out before making the decision to continue pregnancy. ${ }^{14,15}$

Hence timely diagnosis of fetus papyraceus is very important to prevent further complications and have successful surviving fetus outcome. Assuring the parents is very important. Maternal consumptive coagulopathy due to fetal demise of one twin is a rarest reported complication. ${ }^{16,17}$

\section{Conclusion:}

We report a case of Fetus Papyraceous with maternal coagulopathy during pregnancy and no complications in the post-partum period. The etiology of the fetus papyraceous could not be explained. Routine ultrasound examination with better training and use of modern ultrasound machines with good resolution is important for detection of multiple gestations. This will allow the diagnosis of fetus papyraceous early in pregnancy and may prevent future obstetrical complications and reduce the risk of mortality and morbidity for the surviving fetus.

\section{References:}

1. Fisk NM. Multiple pregnancy. In: Edmonds DK, editor. Dewhurst's Textbook of Obstetrics and Gynaecology for Postgraduates. Oxford: Blackwell; 2007. pp. 181-91. 
2. Bush M, Pernoll ML. Multiple pregnancy. In: DeCherney $\mathrm{AH}$, Nathan L, editors. Current Obstetric and Gynecologic Diagnosis and Treatment. New York: McGraw-Hill; 2003. pp. 315-25.

3. Fusi L, Gordon H. Twin pregnancy complicated by single intrauterine death. Problems and outcome with conservative management. $\mathrm{Br} \mathrm{J}$ Obstet Gynaecol. 1990;97:511-6. [PubMed]

4. Jellife DB. Prematurity. In: Lawson JB, Stewart DB, editors. Obstetrics and Gynaecology in the tropics and developing countries. London: Edward Arnold (Publishers); 1979. pp. 253-76.

5. Teliga-Czajkowska J, Dadalska E, Sopliñski A. Triplet pregnancy complicated by intrauterine death of two fetuses: Case report. Ginekol Pol. 2003;74:1302-5. [PubMed]

6. Bozkurt M, Kara D. Fetus papyraceous in a twin pregnancy: A case report without any maternal and fetal complications. Proc Obstet Gynecol 2013;3:1-5.

7. Rahman H, Pathak R, Dubey S, Chavan P, Sharma BK, Khalda E. Fetus papyraceous in univovular twin: Death of one twin in early third trimester and successful outcome of other twin at term: A rare case report. Gen Med 2013;1:14.

8. Novak CM, Patel SV, Baschat AA, Hickey KW, Petersen SM. Maternal coagulopathy after umbilical cord occlusion for twin reversed arterial perfusion sequence. Obstet Gynecol 2013;122:498-500.

9. Finley BE. Acute coagulopathy in pregnancy . Med Clin North Am 1989; 73: 723-43
10. Weiner AE, Reid DE, Roby CC, Diamond LK. Coagulation defects with intrauterine death from $\mathrm{Rh}$ isosensitization. Am J Obstet Gynecol 1950:60: 1015-22

11. Daw E. Fetus papyraceus-11 cases. Postgrad Med J. 1983;59(695):598-600.

12. Benirschke K. Intrauterine death of a twin: Mechanisms, implications for surviving twin, and placental pathology. Semin Diagn Pathol 1993;10(3):222-31.

13. Akbar M, Ikram M, Talib W, Saeed R, Saeed M. Fetus papyraceous: demise of one twin in second trimester with successful outcome of second twin at term. Professional Med J. 2005; 12:351-3.

14. Hagay ZJ, Mazor M, Leiberman JR. Multiple pregnancy complicated by a single intrauterine fetal death. Obstet Gynecol 1985; 66(6): 837838.

15. Hagay ZJ, Mazor M, Leiberman JR, Biale Y. Management and outcome of multiple pregnancies complicated by the antenatal death of one fetus. J Reprod Med 1986; 31(8): 717720.

16. Ong SS, Zamora J, Khan KS, Kilby MD. Prognosis for the co-twin following single-twin death: A systematic review. BJOG 2006;113(9):992-8.

17. Novak CM, Patel SV, Baschat AA, Hickey KW, Petersen SM. Maternal coagulopathy after umbilical cord occlusion for twin reversed arterial perfusion sequence. Obstet Gynecol. 2013 Aug;122(2 Pt 2):498-500. 